\title{
Evaluation of in-Hospital Cardiac Arrest Patients
}

\section{öz}

Amaç: Kardiyak arrest, kardiyak fonksiyonların durması veya büyük arterlerde nabız alınamaması; solunum ve bilinç kaybı ile karakterize ani ve beklenmedik şekilde gelişen bir klinik tablodur. Bu çalışmada, hastane içi kardiyak arrest olguların prospektif olarak değerlendirilmesi amaçlanmıştır. Yöntem: Hastane içinde gelişen erişkin arrest olgular, kardiyopulmoner resüsitasyon (KPR) işlemi ile birlikte değerlendirmeye alındı. Yaș, cinsiyet, beden kitle indeksi (BMI), hastalık grupları, arrest sırasındaki kardiyak ritim, arreste neden olan geri döndürülebilir nedenler, kullanılan ilaç dozları, spontan dolaşım geri dönüşs süresi, kan basıncı değerleri kaydedildi. Tüm veriler SPSS 15.0 istatistik programında uygun testler yapılarak değerlendirildi ve $p<0.05$ anlamlı kabul edildi.

Bulgular: Araştırmaya 189 olgu dahil edilmiştir. Olguların yaş ortalaması 58.49 \pm 16.78 dir. Olguların 71'i (\%37.5) kadın ve 118'i (\%62.5) erkektir. Kadınların ( $n=71)$ BMI ortalaması $27.04 \pm 5.78 \mathrm{~kg} \mathrm{~m}^{-2}$, erkeklerin ( $n=118$ ) BMI ortalaması $23.60 \pm 4.37 \mathrm{~kg} \mathrm{~m}^{-2}$ olarak saptandı $(p<0.05)$. Olguların, \%34.9'unda $(n=66) H T$, \%28.5'inde $(n=54) D M, \% 24.3$ 'ünde $(n=46) K A H, \% 12.6$ 'sında $(n=24) K O A H, \% 12.1$ 'inde $(n=23) K B Y, \% 14.2$ 'sinde $(n=27)$ SVO, \%14.2'sinde ( $n=27) K K Y$ ve $\% 6.8^{\prime}$ inde $(n=13)$ geçirilmiş MI mevcuttu. DM kadınlarda daha fazlaydı $(p<0.05)$. Arrest ritimler olarak, NEA (\%18.5) ve asistoli (\%77.2) belirlendi. Arreste neden olan geri döndürülebilir nedenler hipoksi (\%10.6 $n=20)$ ve hipo-hiperkalemi (\%8.5 $n=16)$ en sık görülenlerdi. Resüsitasyon süresi

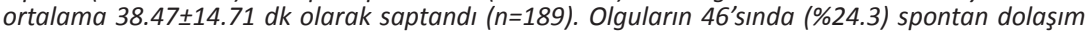
geri döndü, 143'ü (\%75.7) eksitus olarak kabul edildi. Spontan dolaşımı geri dönen olgulara (SDGD) (n=46) uygulanan ortalama resüsitasyon süresi $14.80 \pm 9.07 \mathrm{dk}$ idi. SKB $74.35 \pm 32.63$ $\mathrm{mmHg}, \mathrm{DKB} 45.00 \pm 18.34 \mathrm{mmHg}$ olarak kaydedildi.

Sonuç: Hastane içi arrestlerde nabızsIz elektriksel aktivite (NEA) ve asistoli gibi şoklanamayan ritmler en sık görülen ritmlerdir. SDGD süresinin kısa olması sağ kalım lehinedir. Arreste neden olan geri döndürülebilir nedenler önceden belirlenmeli ve kritik hastaların değerlendirilmesinde acil müdahale ekibi kardiyak arrest olmadan önce haberdar edilmelidir.

Anahtar kelimeler: Hastane içi arrest, KPR, erişkin hasta

\section{ABSTRACT}

Objective: Cardiac arrest is a suddenly developed unexpected clinical condition characterized with cessation of cardiac functions or inability to palpate pulsations in major arteries; loss of respiratory functions and consciousness. The aim of this study was to evaluate prospectively inhospital cardiac arrest cases.

Method: We aimed to evaluate the patients diagnosed with cardiac arrest developed in the hospital using cardiopulmonary resuscitation procedure (CPR). Demographic variables as age, gender, body mass index (BMI), disease groups, reversible causes of cardiac arrest, dosages of drugs used, time to return to spontaneous circulation, heart rhythm during cardiac arrest, and blood pressure values were recorded. All data were evaluated in SPSS 15.0 statistical program using appropriate tests and $p<0.05$ is accepted as the level of statistical significance.

Results: We included 189 patients in the study with a mean age of $58.49 \pm 16.78$ years. Seventyone patients were women (37.5\%), 118 patients were men $(62.5 \%)$. Mean BMls of female $(n=71)$, and male patients $(n=118)$ were $27.04 \pm 5.78 \mathrm{kgm}^{-2}$ and $23.60 \pm 4.37 \mathrm{kgm}^{-2}$, respectively $(p<0.05)$. Respective percentages of patients had experienced HT ( $n=66: 34.9 \%), D M(n=54: 28.5 \%), C A D$ $(n=46: 24.3 \%), \operatorname{COPD}(n=24: 12.6 \%), \operatorname{CRF}(12.1 \%), \operatorname{SVD}(n=27: 14.2 \%), C H F(n=27: 14.2 \%)$ and $\mathrm{MI}$ $(n=13: \% 6.8)$. DM was seen in significantly higher number of women $(p<0.05)$. NEA $(18.5 \%)$, and asystole (77.2\%) were arrest rhythms. The most frequently seen reversible causes that induced arrest were hypoxia ( $n=20: 10.6 \%)$ and hypo-hyperkalemi ( $n=16: 8.5 \%)$. Mean duration of CPR was $38.47 \pm 14.71 \mathrm{~min}$. ( $n=189)$. In the 46 of the patients $(24.3 \%)$, spontaneous circulations returned, and 143 of them (75.5\%) exited. Mean duration of resuscitation applied for patients $(n=46)$ whose spontaneous respiration was recovered was $14.80 \pm 9.07 \mathrm{~min}$. SBP, and DBP were recorded as $74.35 \pm 32.63 \mathrm{mmHg}$, and $45.00 \pm 18.34 \mathrm{mmHg}$, respectively.

Conclusion: In cardiac arrests of in-patiens most frequently non-shockable rhythms such as pulseless electrical activity and asystole are seen. The short duration of cardiac arrest is in favor for survival. Reversible causes of cardiac arrest should be pre-determined and in the evaluation of critical evaluation of patients emergency intervention team should be notified.before development of cardiac arrest.

Keywords: In-hospital arrest, CPR, adult patient
Alındığı tarih: 20.11.2018

Kabul tarihi: 26.12.2018

Yayın tarihi: 31.01.2019

Eralp Çevikkalp

Özel Medicabil Hastanesi

Anesteziyoloji ve Reanimasyon Birimi Ameliyathane Kat, Bursa, Türkiye

eralpcevikkalp@hotmail.com ORCID: 0000-0002-6027-624X

G. Tezcan Keleş 0000-0002-6879-5124 A. Açıkel 0000-0002-6246-9731

i. Topçu 0000-0002-2783-2865

Manisa Celal Bayar Üniversitesi Tıp Fakültesi, Anesteziyoloji ve Reanimasyon Anabilim Dalı, Manisa, Türkiye 


\section{Giriş}

Kardiyopulmoner arrest (KA) hastanede yatan hastalarda herhangi bir zamanda ortaya çıkabilen yüksek mortalitesi olan bir durumdur ${ }^{(1)}$. Hastane içi arrestlerde; etiyoloji, sağ kalım ilişkili koşullar çok farklı nedenlerden kaynaklanabilir. Kardiyopulmoner resüsitasyon (KPR) uygulamalarının tek amacl; erken spontan dolaşım geri dönüşü (SDGD) ve sekelsiz iyileşmeyi sağlamaktır ${ }^{(2)}$. Hızlı müdahalenin yanı sıra hastanın erken dönemde kötüleşmeden tanınması ve oluşabilecek arrestin önlenmesi yaşam kurtarma zincirindeki ilk halkadır (3). Avrupa Resüsitasyon Derneği (ERC), hastaların arrest olmadan önce erken tanınmasında personel eğitimi, hasta monitorizasyonu, kötüleşmekte olan hastanın tanınması ve yardım çağrılması, efektif yanıt için çağrı sistemleri ve acil müdahale ekiplerinin kurulması gerektiğini vurgulamaktadır ${ }^{(4)}$. Durumu kötüleşen hastalarda, olası kardiyak arrest nedenlerinin sorgulanması ve gelişen KA sonrası da standart KPR algoritmaların uygulanması tüm sağlık kurumlarının ana hedefidir.

Bu çalışmada, birincil hedefimiz olarak; ülkemizde bir üniversite hastanesi içinde gelişen hastane içi kardiyak arrest olguların hastalık gruplarını, arrest ritimlerini, KPR süresi ile mortalite oranlarını, acil müdahale ekiplerinin etkinliğini araştırmayı amaçladık.

\section{GEREÇ ve YÖNTEM}

Manisa Celal Bayar Üniversitesi Tıp Fakültesi Girişimsel Olmayan Klinik Çalışmalar Etik Kurulu onayı (Karar No: 20.478.486-240) alındıktan sonra bu prospektif çalışmaya başlandı.

Çalışma popülasyonu; CBÜTF Hafsa Sultan Hastanesi 800 yataklı hasta bakımına uygundur. Hastanede yoğun bakım ünitesi, dahili ve cerrahi yataklı servislerde yatarak tedavi gören, Aralık 2013 - Ocak 2016 tarihleri arasında tedavileri sırasında hastane içinde arrest gelişen erişkin olgular çalışmaya dahil edildi.

Çalışma protokolü; hastane içi kardiyak arrestler için uygulanan tedavilerin ve hasta özelliklerinin tüm verileri, "Utstein Style" formu ${ }^{(5)}$ kullanılarak kaydedildi. Çalışmaya dahil edilen tüm olgular anabilim dalımız asistanları tarafından resüsite edildi, çalışma ekibindeki öğretim üyeleri tarafından değerlendirildi.
Ayrıca tüm servis hemşirelerine ERC ileri yaşam desteği eğitimi verildi. Utstein Style formunda bulunan (5) olguların yaș, kilo, cinsiyet, beden kitle indeksi (BMI), hastalık grupları, arrest tanısı sırasındaki kardiyak ritm, arreste neden olan geri döndürülebilir nedenler, spontan dolaşım geri dönüş (SDGD) süresi, kullanılan adrenalin dozu ve diğer ilaçlar, kan basıncı, hastaların nörolojik skorlamaları kayıt altına alındı.

\section{İstatistiksel analiz}

Gruplar arası karşılaştırmalarında, iki grup arasında yapılan karşılaştırmalarda Mann Whithey testi kullanıldı. Kategorik değişkenlerin gruplar arası karşılaştırmaları Pearson ki-kare ya da Fisher'in kesin ki-kare testi kullanılarak yapıldı. Çalışmanın analizleri SPSS 15.0 istatistik programında yapılarak, $p<0.05$ istatistiksel olarak anlamlı olarak kabul edildi.

\section{BULGULAR}

Çalışma süresi içerisinde 196 hasta verisi kaydedildi. Toplam 196 olgunun 7'si acil servise 112 ekipleri tarafından KPR yapılarak getirildiği için bu olgular hastane dışı arrest olarak kabul edildi ve çalışmaya dahil edilmedi. Hastane içi arrest olan ve KPR uygulanan 189 olgunun verileri çalışmaya alındı.

Olguların ( $n=189$ ) 71'i (\%37.5) kadın ve $118^{\prime} i$ (\%62.5) erkek, yaş ortalaması $58.49 \pm 16.78$ yıl, yaş dağılımı $18-88$ yaş aralığındadır. Erkeklerin $(n=118)$ yaş ortalaması $57.45 \pm 16.53$, yaş dağılımı $18-88$ yaş, kadınların $(n=71)$ yaş ortalaması $60.21 \pm 17.06$, yaş dağııımı 20-88 yaş aralığındadır. Kadınların ( $n=71$ ) BMI ortalaması $27.04 \pm 5.78 \mathrm{~kg} \mathrm{~m}^{-2}$, erkeklerin $(n=118)$ BMI ortalaması $23.60 \pm 4.37 \mathrm{~kg} \mathrm{~m}^{-2}$ olarak saptandı. BMI değerleri açısından kadınların BMI değerleri erkeklere oranla daha fazladır $(p<0.05)$ (Tablo I).

Olguların ( $n=189$ ) geçmiş öykülerinde; \%34.9'unda ( $n=66) H T, \% 28.5^{\prime}$ inde ( $\left.n=54\right)$ DM, \%24.3'ünde ( $\left.n=46\right)$ $\mathrm{KAH}, \% 12.6$ 'sında $(n=24) \mathrm{KOAH}, \% 12.1^{\prime}$ inde $(n=23)$ KBY, \%14.2'ünde ( $n=27)$ SVO, \%14.2'sinde ( $n=27)$ KKY ve $\% 6.8^{\prime}$ inde $(n=13)$ geçirilmiş MI mevcuttu. Yandaş hastalıklarda cinsiyetler arasında anlamlı fark saptanmazken, yalnızca DM kadınlarda istatistiksel anlamlı olarak yüksek bulundu $(p<0.05)$ (Tablo I).

Olguların ( $n=189$ ) hastaneye geliş nedenleri içinde, $\% 20.1^{\prime}$ inde $(n=38)$ genel durum bozukluğu, 
Tablo I. Hastane içi kardiyak arrest olguların demografik verileri

\begin{tabular}{lccc}
\hline & Kadın & Erkek & P değeri \\
\hline Olgu sayısı n (\%) & $71(37.5)$ & $118(62.5)$ & 0.08 \\
Yaş & $60.21 \pm 17.06$ & $57.45 \pm 16.53$ & 0.594 \\
BMI (kg m ${ }^{-2}$ ) & $27.044 \pm 5.785$ & $23.607 \pm 4.370$ & $0.001^{*}$ \\
Yandaş hastalıklar $\mathbf{n}$ (\%) & $5(7)$ & $19(16)$ & 0.053 \\
KOAH & $28(39)$ & $26(22)$ & $0.009^{*}$ \\
DM & $29(39)$ & $37(31)$ & 0.122 \\
HT & $18(25)$ & $28(23)$ & 0.466 \\
KAH & $6(8)$ & $21(17)$ & 0.056 \\
SVO & $13(18)$ & $14(11)$ & 0.156 \\
KKY & $4(6)$ & $9(7)$ & 0.419 \\
Geçirilmiş MI & $10(14)$ & $13(11)$ & 0.342 \\
KBY & $17(23)$ & $21(17)$ & 0.244 \\
Hastaneye yatış nedeni $\mathbf{n}$ (\%) & $15(21)$ & $13(11)$ & 0.762 \\
GDB & $13(18)$ & $26(22)$ & 0.100 \\
SY/pnömoni & $10(14)$ & $15(12)$ & 0.214 \\
Post KPR & $4(5)$ & $10(8)$ & 0.576 \\
Akut battn & $4(5)$ & $19(16)$ & 0.374 \\
Göğüs ağrısı & & \\
Travma & & & \\
\end{tabular}

KOAH: Kronik obstrüktif akciğer hastalığı, DM: diyabetes mellitus, HT: hipertansiyon, SVO: serebrovasküler olay KAH: koroner arter hastalığı, KBY: kronik böbrek yetmezliği, MI: myokard infarktüsü, KKY: konjestif kalp yetmezliği, GDB: genel durum bozukluğu, sY: solunum yetmezliği, $*=p<0.05$

$\% 14.8$ 'inde $(n=28)$ solunum yetmezliği/pnömoni, $\% 20.6$ 'sında $(n=39)$ post KPR, \%13.2'sinde $(n=25)$ akut batın, \%7.4'ünde $(n=14)$ göğüs ağrısı ve \%12.1'inde $(n=23)$ travma bulunmaktadır. Geliş nedenleri arasında cinsiyetler arası anlamlı fark saptanmamıştır ( $p>0.05$ ) (Tablo I).

Hastane içi gerçekleşen arrestlerin $(n=189)$ içinden \%67.7'si (n=128) anestezi YBÜ, \%11.6'sı (n=22) acil serviste, \%7.9'u ( $n=15)$ dahiliye YBÜ, \%8.5'i ( $n=16)$ cerrahi YBÜ ve \%4.2'si (n=8) diğer servislerde gerçekleşti.

KPR ekibinin hastane içi servislerde arrest olgulara ortalama erişim zamanı $0.52 \pm 1.23 \mathrm{dk}$, anestezi YBÜ'de ortalama $0 \pm 0.01 \mathrm{dk}$, anestezi YBÜ dışındaki servislerde ortalama $1.61 \pm 1.72 \mathrm{dk}(\mathrm{n}=61)$ olarak bulundu. AYBÜ arreste müdahale zamanı AYBÜ dışındaki servislerde müdahale zamanına göre anlamlı olarak düşüktür $(p<0.05)$.

Tablo II. Serviste görülen arrest ritimleri

\begin{tabular}{lccc}
\hline & Kadın n (\%) & Erkek n (\%) & P değeri \\
\hline NEA & $14(19.7)$ & $21(17.8)$ & 0.594 \\
Nabızsız VT & $1(1.4)$ & $1(0.8)$ & 0.912 \\
VF & $2(2.8)$ & $4(3.4)$ & 0.180 \\
Asistoli & $54(76.1)$ & $92(78)$ & 0.314 \\
\hline
\end{tabular}

NEA: nabızsız elektriksel aktivite, VT: ventriküler taşikardi, VF: ventriküler fibrilasyon
Olgularda ilk kardiyak arrest ritmi olarak en sık NEA (\%18.5) ve asistoli (\%77.2) saptandı (Tablo II). Arrest ritimleri açısından kadın ve erkeklerde cinsiyet arasında fark saptanmadı ( $p>0.05)$.

Arreste neden olan geri döndürülebilir nedenler; hipoksi (\%10.6, $\mathrm{n}=20$ ) ve hipo/hiperkalemi (\%8.5, $n=16)$, hipovolemi (\%4.2, $n=8)$, tromboemboli (\%1.6, $\mathrm{n}=3$ ) ve tansiyon pnömotoraks (\%1.1, $\mathrm{n}=2$ ) olarak sıralandı (Tablo III).

Hastane içi servislerde arresti takiben uygulanan ortalama resüsitasyon süresi 38.47 $\pm 14.71 \mathrm{dk}(\mathrm{n}=189)$ bulundu. Hastane içi arrest gelişen olguların 46'sında (\%24.3) (24'ü AYBÜ ve 22'si diğer servislerde) spontan dolaşım geri döndü. Olguların 143'ü (\%75.7), KPR

Tablo III. Arrestin olduğu servisler ve geri döndürülebilir nedenler

\begin{tabular}{lc}
\hline & Hasta sayısı n (\%) \\
\hline Geri döndürülebilir nedenler & $20(10.6)$ \\
Hipoksi & $16(8.5)$ \\
Hipo/Hiperkalemi & $8(4.2)$ \\
Hipovolemi & $3(1.6)$ \\
Tromboemboli & $2(1.1)$ \\
Pnömotoraks & \\
Servis & \\
Anestezi yoğun bakım & $128(67.7)$ \\
Acil servis & $22(11.6)$ \\
Cerrahi yoğun bakım & $16(8.5)$ \\
Dahiliye yoğun bakım & $15(7.9)$ \\
Diğer & $8(4.2)$ \\
\end{tabular}




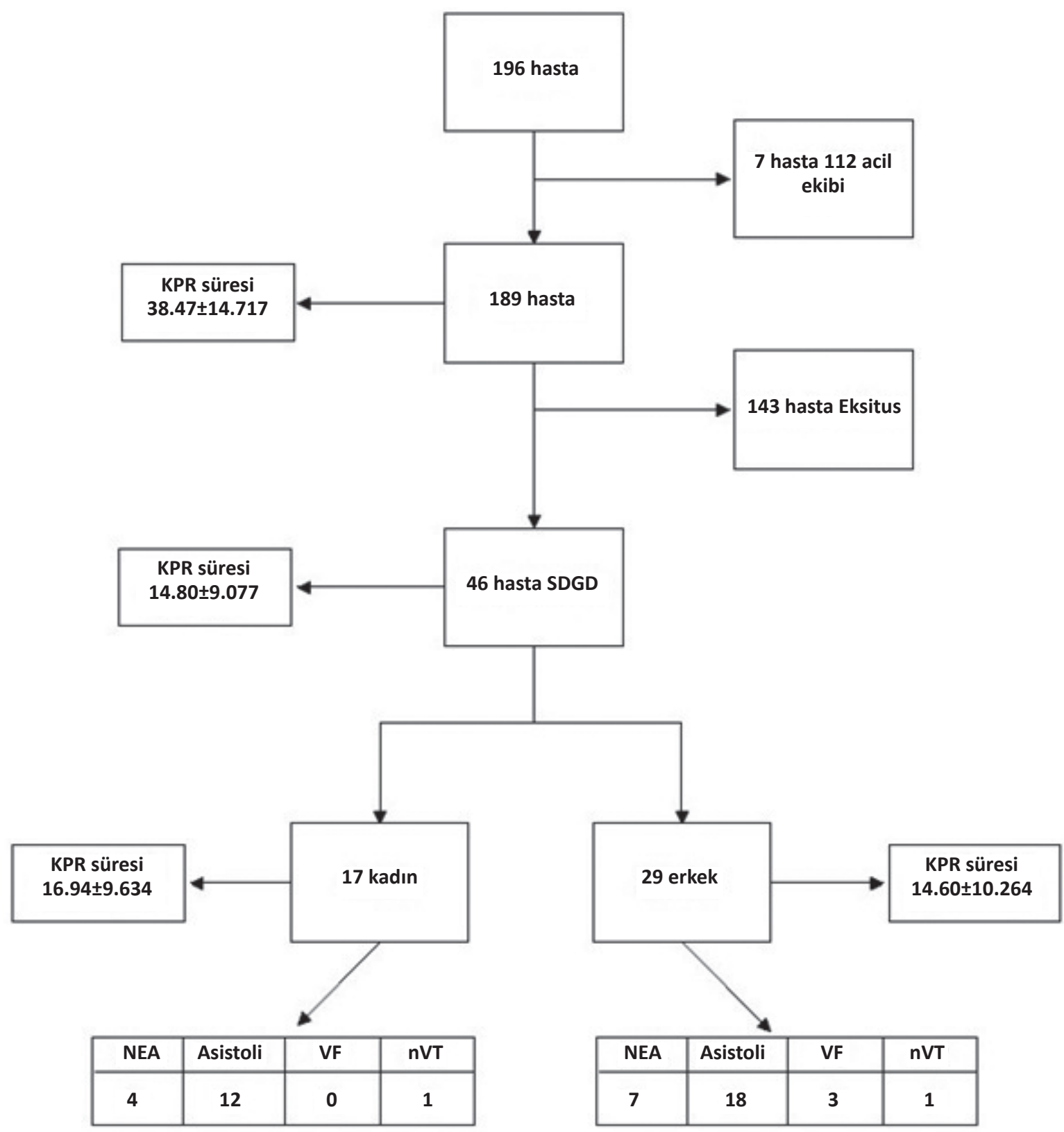

Şekil 1. SDGD hastaların diyagramı

sonrası eksitus olarak kabul edildi. Spontan dolaşım geri dönen olgulara $(n=46)$ uygulanan ortalama resüsitasyon süresi $14.80 \pm 9.07$ dk'dır. Kadın olguların ( $n=17$ ) resüsitasyon süresi ortalaması $16.94 \pm 9.63 \mathrm{dk}$ ve erkek olguların $(n=29)$ resüsitasyon süresi ortala-

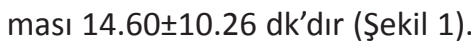

Olguların kardiyak arrest teyidi için, 125'ine (\%66.1) karotis nabzı, 64'üne (\%33.9) femoral nabız bakılarak tanı konmuştur.
Spontan dolaşım geri dönen olgularda $(n=46)$, sistolik kan basıncı ortalaması $74.35 \pm 32.63 \mathrm{mmHg}$, diastolik kan basıncı ortalaması $45.00 \pm 18.34$ mmHg'dır.

Spontan dolaşım geri dönen olguların $(n=46)$, medikal tedavilerinde; 23'üne (\%50.0) dopamin, 25'ine (\%54.3) noradrenalin, 19'una (\%41.3) dobutamin, 6'sına (\%13.0) atropin, 5'ine (\%10.9) amiodaron ve 15 'ine (\%32.6) adrenalin infüzyon uygulandı.

Olgularda KPR sırasında endikasyon dahilinde kulla- 


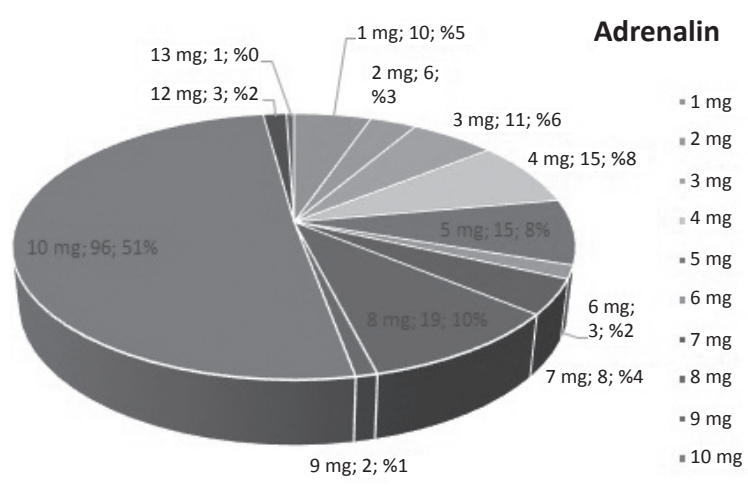

Şekil 2. KPR sırasında uygulanan adrenalin miktarı (mg)

nılan 1 mg'lık dozlarda adrenalin uygulama sayısı ortalama 7.63 \pm 3.10 'dur. Doksan altı olguda (\% 50.8) 1 mg'lık adrenalin uygulaması 10 kez yapılmıştır (Şekil 2).

\section{TARTIŞMA}

Hastane içi kardiyak arrestler göreceli olarak öngörülebilen olaylardır. Hastaların sağ kalım ve taburculuk oranları \%20'den azdır ${ }^{(6,7)}$. Bu çalışmayı, bir üniversite hastanesi içinde gelişen kardiyak arrestlerin periarrest durumları incelemek amacı ile prospektif klinik gözlemsel çalışma olarak gerçekleştirdik.

Çalışmamızın verileri doğrultusunda bulduğumuz en önemli sonuçlar şunlardır:

1-Arrestin en sık görüldüğü hasta grupları genel durum bozukluğu, solunum yetmezliği/pnömoni ve daha önce arrest nedeniyle yoğun bakımda post resüsitatif bakımı için takip edilen hastalar oluşturdu.

2-Hastane içi arrestlerde, kardiyak arrest ritmi olarak en sık nabızsız elektriksel aktivite (NEA) ve asistoli ritimleri görüldü.

3-Anestezi YBÜ içindeki arrestlerin müdahale zamanı, diğer servislerde müdahale zamanına göre anlamIı olarak kısa bulundu.

4-KPR uygulanan kadınlarda, erkeklere oranla vücut kitle indeksleri ve diyabetes mellitus görülme sıklığı daha yüksekti.

Çalışmamıza dahil edilen hastaların demografik verileri incelendiğinde, yaş ortalaması $58.74 \pm 16.6$ olup, \%62.8'i erkek ve \%37.2'si kadın olarak bulunmuştur. Bulgularımız literatür ile uyumludur. Taha ve ark' $n ı{ }^{(8)}$ çalışmasında, yaş ortalaması 56.4 $\pm 14.8, \% 63.5$ erkek,

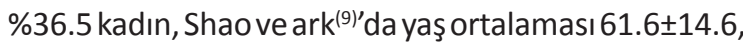
\%67.8 erkek, \%32.2 kadın olarak belirtmiştir.
Hastane içi arrestlerde en sık NEA ve asistoli ritimleri görülmektedir ${ }^{(7-11)}$. Şok uygulanabilir ritimler (nVT,VF) görülen olgularda hastaların resüsitasyona yanıtı şok uygulanamaz ritimlere göre daha iyidir ${ }^{(7,9,12)}$. Çalışma olgularımız için kardiyak arrest ritimlerinde en sık NEA ve asistoli görülmüştür, literatür verileri ile uyumludur. Kardiyak arrest onayı için klavuzlarda yer alan öneri karotis nabzına bakılarak onaylanmasının daha sağlıklı olduğu şeklindedir. Çalışmamızda, KA onayı için \%66.1 karotis nabzı, \%33.9 oranında femoral nabız bakılmıştır. Çalışma olgularımızın daha büyük oranını yoğun bakım hastalarımız oluşturmaktadır. YB da izlenen, entübe ve mekanik ventilatördeki bir hastada ani gelişen KA'de, hastaya ve pozisyona bağıı olarak femoral nabız bakmanın da çok pratik bir uygulama olduğu düşüncesindeyiz.

Bergum ve ark. ${ }^{(13)}$ çalışmasında, hastaların hastaneye yatış nedenleri arasında en sık neden olarak pulmoner ve kardiyak nedenler olduğunu belirtir. Kardiyak nedenler arasında da en sık miyokard infarktüsü, kalp yetmezliği ve aritmilerdir ${ }^{(12)}$. Çalışmamızda, kardiyak arrest yaratan nedenler arasında en sık pulmoner yetmezlik/pnömoniye bağı olan arrestler, myokard infarktüsü, aritmilere bağlı gelişen kardiyak arrestler sonucu takip edilen hastaların kardiyak arrest olduğu belirlenmiştir.

Arrestin geri döndürülebilir nedenleri arasında, en sık hipoksi ve hipovolemi olduğu belirtilir (13-15). Çalışmamızda en sık görülen geri döndürülebilir nedenler; hipoksi, hiperkalemi ve hipovolemi olarak bulunmuştur. Hiperkaleminin, hipovolemiden daha sık görülmesinin nedeni olarak, hastalarımızın büyük bir çoğunluğu yoğun bakımda ve metabolik sorunlar nedeniyle tedavi gören olgulardan oluştuğu için, çoklu sistemik hastalık ve elektrolit denge bozukluğu nedeniyle olabileceğini düşündük.

Acil müdahale ekiplerinde görev alanlar; genellikle yoğun bakım ve genel tıp alanında görev almış doktor, hemşire, anestezi teknisyeni, paramedik, sağlık teknisyeni personelinden oluşur. Acil müdahale ekiplerinin olaya erken dahil olması, kardiyak arrestleri, ölümleri ve beklenmedik yoğun bakım ünitesi kabulünü azaltabilir ${ }^{(6,15)}$. Bellomo ve ark. ${ }^{(16)}$, acil müdahale ekiplerinin varlığı ile hastane içi kardiyak arrest insidansında (göreceli risk azalması \%65), kardiyak arrest sonrası ölüm oranı (\%56) ve genel hastane içi 
mortalitede (\%88) anlamlı bir azalma olduğunu belirtirler. Benzer bir çalışma olan Buist ve ark. ${ }^{(17)}$ çalışmalarında, beklenmedik kardiyak arrest olgularında (1.000 hastaneye başvuru başına 3.77'den $2.05^{\prime} \mathrm{e}$ ) ve mortalite de (\%77'den \%55'e) önemli bir azalma olduğu gösterilmiştir. Ülkemizde hastane içi kardiyak arrest olgularına hızlı müdahale ve tedavi götürmeyi amaçlayan Mavi Kod sistemi uygulanmaktadır. Sağlık Bakanlığı hastanelerinde karma hekim ve yardımcı sağlık personelinden oluşmasına ve uzun yıllardır daha aktif kullanılmasına karşın, üniversite hastanelerinin pek çoğunda, hastanemizde yeni kurulan acil müdahale ekibinde olduğu gibi bu ekibin personelleri daha çok anestezi yoğun bakım çalışanı doktor ve hemşireleri gibi sağlıkçılardan oluşmaktadır. Anestezi yoğun bakım dışındaki hastalara müdahale zamanı uzamakta ve hastaya ilk müdahale şansı azalmaktadır. Çalışmamızda da spontan dolaşımı geri dönen 46 hastalanın 24'ü anestezi yoğun bakımdaki hastalardan oluşmaktadır ve anestezi yoğun bakımda arreste müdahale zamanı AYBÜ dışındaki birimlerde arreste müdahale zamanına göre anlamlı olarak düşük bulunmuştur.

Kardiyopulmoner arrest hastanede yatan hastalarda herhangi bir zamanda ortaya çıkabilen yüksek mortalitesi olan bir durumdur (1). Yüksek kaliteli göğüs kompresyonları resüsitasyonun başarısı için en önemli belirleyicidir. Son kılavuzda göğüs kompresyonlarının, göğsün genişlemesine izin verecek şekilde yeterli hızda, derinlikte ve duraklamaları en aza indirgeyerek uygulanması vurgulanmış ve 2010 yııında güncellenen kılavuzda resüsitasyon sırasında atropin kullanılmaması yönünde karar alınmıştır. 2015 yılında yayınlanan son kılavuzlarda yine kardiyak arrest ritmlerinde atropin uygulamasına hiç yer verilmemiştir. Çalışmayan kalpte atropinin yeri yoktur. Bizim çalışmamızda da kardiyak arrest olan hiçbir hastada atropin kullanılmamıştır. Yine son 2015 kılavuz bilgilerine göre, adrenalin uygulaması şok uygulanamaz ritmlerde hemen, şok uygulanabilir ritmlerde ise 3. şoktan sonra $1 \mathrm{mg}$ iv olarak uygulanır ve SDGD'ye kadar her 3-5 dk da bir tekrarlanır ${ }^{(18)}$. Wang ve ark ${ }^{(19)}$ çalışmasında kullanılan adrenalin miktarı $8.1 \pm 7.1 \mathrm{mg}$ olarak bulunmuştur. Çalışmaya dahil ettiğimiz olgularımız için kardiyak arrest tedavisi sırasında kullandığımız ortalama adrenalin miktarı $7.63 \pm 3.103 \mathrm{mg}$ olarak bulundu, bu sonuç literatür ile benzerlik göstermektedir.
Çalışmamızdaki en önemli kısıtlayıcılar; spontan dolaşımı dönen olguların taburculuk ve tam iyileşme hallerine ait verilerinin eksikliğidir. Kardiyak arrest sonrası SDGD olgular kısa, orta ve uzun dönemde, başta nörolojik iyileşme takibi olmak üzere, primer ve sekonder hasar açısından da yakın izlenmelidir. Resüsitasyon sonrası nörolojik skorlama Serebral Performans Skoru (Cerebral Performance Score (CPC)) ile değerlendirilmelidir. Mevcut hasta verilerinin taburculuk ve sonrası bulguları kayıtlarımızda yoktur. Bu nedenle bu çalışma yalnızca hastane içi olgularda peri-arrest dönemi kapsayan tüm kardiyak arrest ritimleri ve kardiyak arrest nedenlerini sorgulayan verilerin sunulduğu bir çalışma niteliğindedir. Spontan dolaşımı dönen olguların sağ kalım ve yaşam kalitesini gösteren başka bir çalışma planında, daha uzun dönem izlemleri de ülke verilerimize katkı sağlayacaktır.

Sonuç olarak, yoğun bakım üniteleri gibi, monitörize edilerek yakın takip edilen hastalarda arreste müdahale zamanı daha kısa ve kardiyopulmoner resüsitasyon sonrası spontan dolaşımın geri dönmesi daha fazladır. En sık görülen hastane içi arrest ritimleri NEA ve asistoli olup, Erken Uyarı Sistemleri ve Mavi Kod ekipleri ile resüsitasyon sonrası spontan dolaşım geri dönmesi olasılığı artmaktadır.

\section{KAYNAKLAR}

1. Nolan JP. Cardiac Arrest and Cardiopulmonary Resuscitation. Semin Neurol. 2017;37:5-12. https://doi.org/10.1055/s-0036-1597832

2. Kloeck W, Cummins R, Chamberlain D, et al. The Universal ALS algorithm. An advisorystatement by the Advanced Life Support Working Group of the International Liaison Committee on Resuscitation. Resuscitation. 1997;34:109-113. https://doi.org/10.1016/S0300-9572(97)01100-3

3. Nolan J, Soar J, Eikeland H. The chain of survival. Resuscitation. 2006;71:270-1. https://doi.org/10.1016/j.resuscitation.2006.09.001

4. Fernández Lozano I, Urkía C, Lopez Mesa JB, et al. European Resuscitation Council Guidelines for Resuscitation 2015: Key Points. Rev Esp Cardiol (Engl Ed). 2016;69:588-94. https://doi.org/10.1016/j.recesp.2016.01.034

5. Jacobs I, Nadkarni V, Bahr J, et al. Cardiac arrest and cardiopulmonary resuscitation outcome reports: update and simplification of the utstein templates for resuscitation registries: a statement for healthcare professionals from a task force of the International Liaison Committee on Resuscitation (American Heart Association, European Resuscitation Council, Australian Resuscitation Council, New Zealand Resuscitation 
Council, Heartand Stroke Foundation of Canada, Inter American Heart Foundation, Resuscitation Councils of Southern Africa). Circulation. 2004;110:3385-97. https://doi.org/10.1161/01.CIR.0000147236.85306.15

6. Sandroni C, Nolan J, Cavallaro F, Antonelli M. In-hospital cardiac arrest: incidence, prognosis and possiblemeasurestoimprove survival. Intensive Care Med 2007;33:237-45.

https://doi.org/10.1007/s00134-006-0326-z

7. Nolan JP, Soar J, Smith GB et al. Incidence and outcome of in-hospital cardiac arrest in the United Kingdom National Cardiac Arrest Audit. Resuscitation. 2014;85:987-92.

https://doi.org/10.1016/j.resuscitation.2014.04.002

8. Hesham S. Taha, Sameh WG. Bakhoum, Hussein H. Kasem, Mera AS. Fahim TAHA, Quality of cardiopulmonary resuscitation of in-hospital cardiac arrest and its relation to clinical outcome: An Egyptian University Hospital Experience. The Egyptian Heart Journal. 2015;67:137-43. https://doi.org/10.1016/j.ehj.2014.11.001

9. Shao F, Li CS, Liang LR, Qin J, Ding N, Fu Y. Incidence and outcome of adult in-hospital cardiac arrest in Beijing, China. Resuscitation. 2016;102:51-6. https://doi.org/10.1016/j.resuscitation.2016.02.002

10. Perman SM, Stanton E, Soar J et al. Location of In-Hospital Cardiac Arrest in the United StatesVariability in Event Rate and Outcomes. J Am Heart Assoc. 2016;5:10.

11. Nadkarni VM, Larkin GL, Peberdy MA et al. First documented rhythm and clinical outcome from in hospital cardiac arrest among children and adults. JAMA. 2006;295:50-7.

https://doi.org/10.1001/jama.295.1.50
12. Tan SC, Leong BS. Cardiac arrests with in the emergency department: an Utsteinstyle report, causation and survival factors. Eur J Emerg Med. 2018;25:12-7.

13. Bergum D, Nordseth T, Mjølstad OC, Skogvoll E, Haugen BO.Causes of in-hospital cardiac arrest - incidences and rate of recognition. Resuscitation. 2015;87:63-8. https://doi.org/10.1016/j.resuscitation.2014.11.007

14. Tirkkonen J, Hellevuo H, Olkkola KT, Hoppu S.Aetiology of in-hospital cardiac arrest on general wards. Resuscitation. 2016;107:19-24. https://doi.org/10.1016/j.resuscitation.2016.07.007

15. Jones D, Mercer I, HelandM,et al. In-hospital cardiac arrest epidemiology in a mature rapid response system. Br J Hosp Med (Lond). 2017;78:137-42.

16. Bellomo R, Goldsmith D, Uchino S. et al. Prospective before-and-after trial of a medical emergency team. Med J Aust. 2003;179:283-7.

17. Buist MD, Moore GE, Bernard SA, Waxman BP, Anderson JN, NguyenTV. Effects of a medical emergency team on reduction of incidence of and mortality from unexpected cardiac arrests in hospital: preliminarystudy. BMJ. 2002;324:387-90.

18. Nolan JP, Soar J, Cariou A, et al. European Resuscitation Council and European Society of Intensive Care Medicine Guidelines for Post-resuscitation Care 2015: Section 5 of the European Resuscitation Council Guidelines for Resuscitation 2015. Resuscitation. 2015;95:202-22.

19. Wang $\mathrm{CH}$, Huang $\mathrm{CH}$, Chang WT et al. The influences of adrenaline dosing frequency and dosage on outcomes of adult in-hospital cardiac arrest: A retrospective cohort study. Resuscitation. 2016;103:125-30. https://doi.org/10.1016/j.resuscitation.2015.12.008 